\title{
Testing the influence of environmental heterogeneity on fish species richness in two biogeographic provinces
}

Philippe Massicotte, Raphael Proulx, Gilbert Cabana, Marco A Rodríguez

Environmental homogenization in coastal ecosystems impacted by human activities may be an important factor explaining the observed decline in fish species richness. We used fish community data ( $>200$ species) from extensive surveys conducted in two biogeographic provinces (extent $>1000 \mathrm{~km}$ ) in North America to quantify the relationship between fish species richness and local (grain $<10 \mathrm{~km}^{2}$ ) environmental heterogeneity. Our analyses are based on samples collected at nearly 800 stations over a period of five years. We demonstrate that fish species richness in coastal ecosystems is associated locally with the spatial heterogeneity of environmental variables but not with their magnitude. The observed effect of heterogeneity on species richness was substantially greater than that generated by simulations from a random placement model of community assembly, indicating that the observed relationship is unlikely to arise from veil or sampling effects. Our results suggest that restoring or actively protecting areas of high habitat heterogeneity may be of great importance for slowing current trends of decreasing biodiversity in coastal ecosystems. 


\title{
Testing the influence of environmental heterogeneity on fish species richness in two biogeographic provinces
}

\author{
Philippe Massicotte ${ }^{1,2}$, Raphaël Proulx ${ }^{1}$, Gilbert Cabana ${ }^{1}$, and Marco A. \\ Rodríguez ${ }^{1}$
}

\author{
${ }^{1}$ Centre de Recherche sur les Interactions Bassins Versants-Écosystèmes Aquatiques \\ (RIVE). Université du Québec à Trois-Rivières, 3351, boul. des Forges, G9A 5H7, \\ Trois-Rivières, Canada \\ ${ }^{2}$ Present address: Department of Bioscience. Aarhus University, Frederiksborgvej 399, \\ DK-4000 Roskilde, Denmark
}

\begin{abstract}
Environmental homogenization in coastal ecosystems impacted by human activities may be an important factor explaining the observed decline in fish species richness. We used fish community data $(>200$ species) from extensive surveys conducted in two biogeographic provinces (extent $>1000 \mathrm{~km}$ ) in North America to quantify the relationship between fish species richness and local (grain $<10 \mathrm{~km}^{2}$ ) environmental heterogeneity. Our analyses are based on samples collected at nearly 800 stations over a period of five years. We demonstrate that fish species richness in coastal ecosystems is associated locally with the spatial heterogeneity of environmental variables but not with their magnitude. The observed effect of heterogeneity on species richness was substantially greater than that generated by simulations from a random placement model of community assembly, indicating that the observed relationship is unlikely to arise from veil or sampling effects. Our results suggest that restoring or actively protecting areas of high habitat heterogeneity may be of great importance for slowing current trends of decreasing biodiversity in coastal ecosystems.
\end{abstract}

Keywords:

\section{INTRODUCTION}

The environmental heterogeneity hypothesis (MacArthur and MacArthur, 1961; MacArthur and Wilson, 1967; Ricklefs, 1977) states that species richness increases with the number of ecological niches; that is, species coexistence is facilitated in more heterogeneous environment because different taxa can capitalize on different environmental conditions. The hypothesis has been tested using many taxonomic groups across different spatial grains (average distance among observations) and extents (size of the whole study area) ranging from meters to thousands of kilometers. An extensive meta-analysis by Field et al. (2009) found that environmental heterogeneity was the primary factor driving species richness for 63 of the 273 cases $(23 \%)$ assessing the relative importance of environmental heterogeneity versus other environmental factors. Environmental heterogeneity, however, had a stronger effect on species richness in studies conducted at small grain sizes (39\% of the cases), suggesting that the relationship is contingent on the spatial scale. Furthermore, only 4 of the 393 relationships (1\%) were from surveys of aquatic ecosystems having small grain size $\left(<10 \mathrm{~km}^{2}\right)$ and large geographical extent $(>1000 \mathrm{~km})$. Thus there appears to be no consensus on the effects of small-grain environmental heterogeneity on species richness when investigated over large geographical areas.

This paucity of broad-scale studies may be related to the difficulties faced by aquatic ecologists in quantifying heterogeneity across different temporal and spatial scales (Kovalenko, Thomaz, and Warfe, 2011; Yeager, Layman, and Allgeier, 2011; Tisseuil et al., 2013) possibly reflecting the difficulties of obtaining the data needs to quantify such relationship. As a consequence, the term 'heterogeneity' has been used rather loosely, as it could refer to habitat complexity, habitat diversity or environmental variability in both space and time (Palmer, Menninger, and Bernhardt, 2010). For example, Oberdorff et al. 
(2011) assessed habitat heterogeneity at the continental scale using the proportion of different biomes found within river drainage basins, whereas Guégan, Lek, and Oberdorff (1998) used the mean annual flow discharge as a proxy for environmental heterogeneity in 183 rivers throughout the world. Although these two studies found a positive relationship between heterogeneity and fish species richness, their measures of environmental heterogeneity were confounded with biogeographic factors, such as the size of the drainage area and with other global environmental descriptors including seasonality of rainfall in lotic systems. Recent meta-analyses of the relationship concluded that environmental homogenization has a consistent and negative impact on animal diversity (Smokorowski and Pratt, 2007; Seiferling, Proulx, and Wirth, 2014).

Empirical evidence of the relationship between local (small grain) fish species richness and environmental heterogeneity remains sparse for aquatic ecosystems of broad spatial extent. Further evaluation of the relationship is needed, especially when considering that: 1) species richness is declining in both freshwater and marine ecosystems (Ricciardi and Rasmussen, 1999; Worm et al., 2006), and 2) aquatic ecosystems are increasingly impacted by human activities, such as systematic embankment, river damming and seafloor trawling that are causing environmental homogenization (Lotze, Reise, et al., 2005; Jackson, 2008) as well as changes in water quality variables (Rabalais, 2002). Fish communities are affected by structural characteristics of the environment such as reef structure and the presence of vegetation (Kuffner et al., 2006) and also by water quality such as salinity, turbidity, and oxygen concentration (Rabalais, 2002; Bejarano and Appeldoorn, 2013). The objective of this study was to evaluate the effect of local environmental heterogeneity in environmental variables (spatial grain $<10 \mathrm{~km}^{2}$ ) on fish species richness at the scale of biogeographic regions (spatial extent $>1000 \mathrm{~km}$ ). We used data on fish communities (26 orders, 73 families, 136 genera, 204 species), obtained from extensive surveys in two coastal ecosystems of North America. Using a set of environmental variables routinely measured by monitoring programs, we demonstrate that fish species richness in coastal ecosystems responds positively to the spatial heterogeneity of environmental conditions and quantify the magnitude of this effect. We implemented a random placement model of community assembly to ensure that the empirical relationship found between species richness and environmental heterogeneity did not result of a veil or sampling effect.

\section{MATERIAL AND METHODS}

\section{Study site and data collection}

Fish abundances and environmental measurements were obtained from two extensive surveys conducted by the by the U.S. Environmental Protection Agency's Environmental Monitoring and Assessment Program (EMAP). The first data set consisted of four sampling campaigns conducted in the Virginian biogeographic province between 1990 and 1993 (Hale et al., 2002). Stations were located along the coastline and in large river estuaries of the East Coast (Delaware, Hudson, Potomac, York; Fig. 1A). The second data set was assembled from four sampling campaigns conducted in the Louisianan biogeographic province between 1991 and 1994. Stations were located along the Gulf of Mexico from the Rio Grande, Texas, to Anclote Island, Florida (Fig. 1B). Field campaigns in the two biogeographic provinces were carried out between July and September of each year.

Fish were sampled using balloon trawls (funnel-shaped nets, $4.9 \mathrm{~m}$ wide with $2.5 \mathrm{~cm}$ stretched mesh) deployed from a research vessel using a hydraulic-powered boom in the vicinity of the sampling stations. The duration of the trawl was $10 \pm 2$ (mean \pm SD) minutes at a speed of 2-3 knots. This corresponds to a length of $0.77 \pm 0.15$ (mean $\pm \mathrm{SD}$ ) $\mathrm{km}$. Following a successful trawl, the net was hauled aboard and the catch was released into a plastic trough, or a fish sorting table, where species composition and abundance were recorded (see Appendix S1 in Supporting Information). A total of 2237 individuals (fork length: min. $=2.2 \mathrm{~cm}$; $\max .=91.18 \mathrm{~cm}$; mean $\pm \mathrm{SD}=12.08 \pm 7.33 \mathrm{~cm}$ ) were captured from the Louisianan biogeographic province and 1883 individuals (fork length: min. $=2.5 \mathrm{~cm}$; max. $=92.6 \mathrm{~cm} ;$ mean $\pm \mathrm{SD}=$ $16.03 \pm 10.37 \mathrm{~cm}$ ) were captured from the Virginian biogeographic province, yielding a total of 4120 individuals (Table 1, Appendix S1).

The environmental data comprised physical and chemical measurements. Dissolved oxygen concentrations $\left(\mathrm{mg} \times \mathrm{L}^{-1}\right)$ were determined using an air-calibrated oxygen meter (Yellow Springs Instruments) on surface water samples $(625 \mathrm{~mL})$ obtained with a Go-Flo bottle. Salinity (ppt), temperature $\left({ }^{\circ} \mathrm{C}\right), \mathrm{pH}$, transmissivity ( $\%$ of ambient light transmitted through the water column), photosynthetically active 
radiation $\left(\mu \mathrm{E} \times \mathrm{m}^{-2} \times \mathrm{s}^{-1}\right)$, fluorescence (unitless) and water density $\left(\sigma \mathrm{t}, \mathrm{kg} \times \mathrm{m}^{-3}-1000\right)$ were measured using a SeaBird CTD meter lowered through the water column at a rate of approximately 0.25 $\mathrm{m} \times \mathrm{s}^{-1}$ until it reached the bottom (Table 1). Fluorescence and water density data were not available for the Louisianan surveys. Implicit to our approach is that the gradient of environmental conditions captures a range of habitat and resource types. For example, temperature and dissolved oxygen may to some degree correlate with water depth or nutrient loading, whereas the photosynthetically active radiation is a more direct measure of primary production in the water column. Other variables, such as salinity, impose physiological constraints to the distribution of fish species in coastal transition zones. Detailed information about the sampling and analytical procedures can be found on the EMAP web site (http://www.epa.gov/emap/index.html). Although other environmental variables such as macrophyte cover might be important determinants of environmental heterogeneity, the selected variables are known to affect the ecology of individual fish species (Mandrak, 1995).

\section{Environmental heterogeneity}

To represent the gradient of environmental conditions among stations of the same biogeographic province, we used the scores of a principal component analysis (PCA) performed on the environmental variables. The first three PCA axes (Table 1) were retained based on Kaiser's criterion (Kaiser, 1960) and explained nearly $75 \%$ of the environmental variability in both Virginian $(\mathrm{PC} 1=42.28 \%, \mathrm{PC} 2=19.7 \%, \mathrm{PC} 3=$ $12.6 \%)$ and Louisianan $(\mathrm{PC} 1=32.5 \%, \mathrm{PC} 2=23.8 \%, \mathrm{PC} 3=19.6 \%)$ biogeographic provinces. We quantified the degree of local spatial autocorrelation in environmental conditions near each station as a reciprocal measure of environmental heterogeneity.

We calculated the local Moran $I$ statistic on the scores of the first three PCA axes using the localmoran function of the spdep package in R (Bivand et al., 2013). Only the first PCA axis was retained for further analysis because we did not find any relationship between Moran's $I$ calculated for PCA axes 2 or 3 and species richness. The Moran $I$ statistic identifies station neighborhoods where environmental conditions of similarly high or low values cluster spatially (high $I$ ), as well as neighborhoods where environmental conditions are more contrasted (low $I$ ). High $I$ values indicate low heterogeneity (positive autocorrelation), whereas values around zero indicate high heterogeneity. Negative $I$ values indicate local over-dispersion patterns (i.e., negative autocorrelation), which are rarely observed in nature (Borcard, Gillet, and Legendre, 2011). The I statistic is given by Anselin (1995):

$$
I=(n-1) \frac{x_{i}-\bar{X}}{\sum_{i=1}^{n}\left(x_{i}-\bar{X}\right)^{2}} \sum_{j=1}^{n} w_{i j}\left(x_{j}-\bar{X}\right)
$$

where $x_{i}$ is the value of the observation $i, \bar{X}$ is the mean of the variable, $w_{i j}$ is the spatial weight $\left(1 /\right.$ distance $^{2}$ ) between observations $i$ and $j$, and $n$ is the number of stations sampled. Each $I$ (one per station) have been calculated by including all surrounding neighbours in a $75 \mathrm{~km}$ radius using the dnearneigh function of the spdep package. The chosen radius was large enough to include a sufficient number of neighboring stations in the calculation of Moran's $I$ (average number of stations: Virginian $=54.3$; Louisianan $=52.7$ ), while small enough to prevent the inclusion of stations that are only remotely connected. Spatial weights were scaled as $1 /$ distance $^{2}$ in equation 1 , thus varying the search radius had little effect on $I$ values. Because we could not determine whether patterns of over-dispersion should be associated with high or low levels of environmental heterogeneity, the few stations (less than $4 \%$ ) with negative $I$ values were removed from subsequent statistical analyses. We did not find substantial differences between results for $I$ calculated using all the data pooled at the biogeographic level (spatio-temporal $I$ ) and $I$ calculated for each sampling year separately (spatial $I$ ). Consequently, we view $I$ as a measure of spatial heterogeneity in local environmental conditions across space (Appendix S2, Fig. 1, Eq. 1).

\section{Numerical simulations}

We developed a random placement model of community assembly to determine the heterogeneity-species richness relationship in the absence of explicit habitat selection mechanisms. The model has two main components: (1) environmental heterogeneity and (2) species richness, each being simulated independently of the other on a two-dimensional surface (Fig. 2). This approach has been successfully used in various 
ecological studies aiming to highlight the effect of landscape structures on different aspects of animal biodiversity (McGill, 2011; Campos et al., 2013).

The first model component simulates the spatial patterns of environmental conditions (Fig. 2A). Environmental spatial patterns can be modeled as a fractional Brownian function. The spectral density $S(f)$ of a two-dimensional surface follows a power spectrum $S(f) \propto 1 / f^{\beta}$ (Keitt, 2000), where $f$ is frequency and $\beta=1+2 H$. The Hurst exponent $(H)$ controls the degree of auto-correlation in environmental conditions; a large $H(H \longrightarrow 1)$ results in relatively homogeneous spatial patterns, whereas a lower $H(H \longrightarrow 0)$ produces more heterogeneous patterns. To generate the environmental spatial patterns in our simulations, we used the Matlab function noi seonf, which uses the inverse Fourier transformation of a power spectrum with a predetermined Hurst exponent (Kovesi, 2000). This procedure generates 'neutral' landscapes (e.g., With, 1997; Keitt, 2000) that share several statistical properties with environmental patterns observed in nature. The Hurst exponent of the simulated surface was parameterized using the linear slope of the log-log semi-variogram (Gallant et al., 1994) computed on the scores of the first axis of the PCA of environmental conditions, yielding values of $H \approx 0.4$ in both biogeographical provinces.

The second component (Fig. 2B) of our model simulates the random placement of species with different distribution ranges. We based our random placement model of community assembly on two premises (McGill and Collins, 2003; McGill, 2010): (1) the centroid of each species range is determined by sampling from a uniform distribution over the surface and (2) the range size of species is distributed according to a power distribution. McGill and Collins (2003) reported that implementing either a log-normal or a power distribution did not affect the results of random placement model. Each of our simulation runs proceeded as described in algorithm 1. Local species richness is then calculated by summing the overlap of different species ranges. On the basis of the observed regional distributions of the sampled species (Appendix S2, Fig. 3), we used the following parameters to implement the random placement model: $G=1000$, rmin $=10 \mathrm{~km}$ and $\operatorname{rmax}=1000 \mathrm{~km}$.

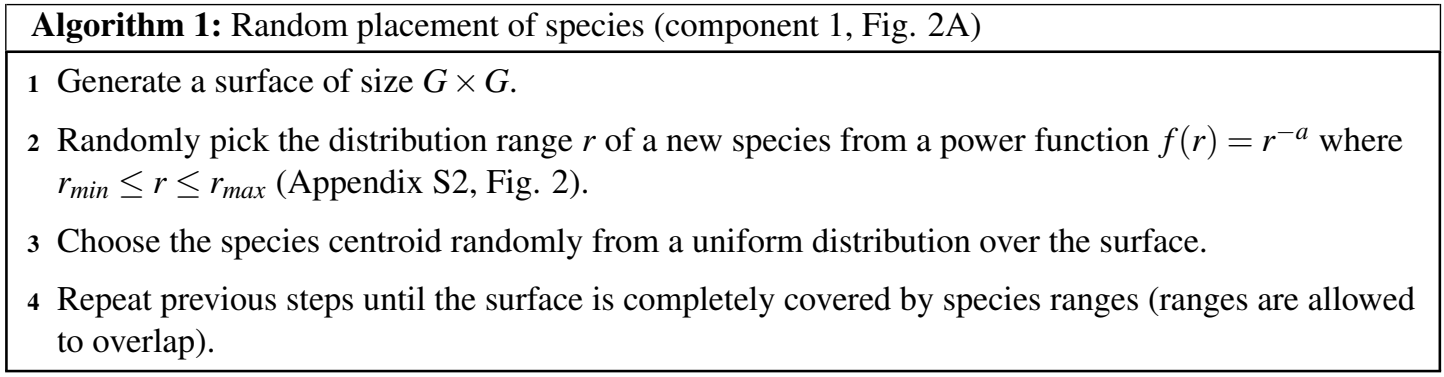

To represent the range of each species on the surface, we used ellipses with major axis length $r$ and minor axis length sampled from a uniform in the interval $[r / 4, r / 2]$ as described in Proulx et al. (2014). To simulate an anisotropic spatial process, we placed the elliptical ranges with their major axis oriented either horizontally (with probability $=0.75$ ) or vertically (with probability $=0.25$ ). This decision was motivated by the fact that species ranges in both biogeographical provinces are preferentially oriented along rivers and coastlines that broadly conform to the proposed alignment. Finally, to determine the parameter $\alpha$ empirically, we calculated the range of all fish species in each biogeographical province (Appendix S2, Fig. 3) and estimated the power coefficient of the frequency using the log-ratio formula (equation 5 in Newman, 2005). We obtained values of $\alpha=1.214$ for the Virginian province and $\alpha=1.189$ for the Louisianan province, and therefore used a value of 1.2 in our simulations. Using different combinations of ellipse shape ratio and orientation, we found that the species richness was robust to these changes. Most importantly, varying the shape ratio and orientation of ellipse (species range) did not affect the general direction and relative effect size of the simulated environmental heterogeneity-species richness relationship. We generated the two model components on grids of $1000 \times 1000$ cells (Fig. 2A and 2B). A total of 10000 simulations where performed according to algorithm 2. It is to be noted that the model does not aim to approximate the absolute number of species at each location. Consequently, we used relative changes in species richness $\left(\Delta_{S}\right)$ to compare modeled and observed results.

In each of the biogeographic provinces surveyed, approximately $5 \%$ of the stations yielded species richness values of zero. These zeros may partly arise from a 'veil effect' (Preston, 1948), and so reflect insufficient sampling effort rather than true absences. Truncation of samples at the veil may induce a 


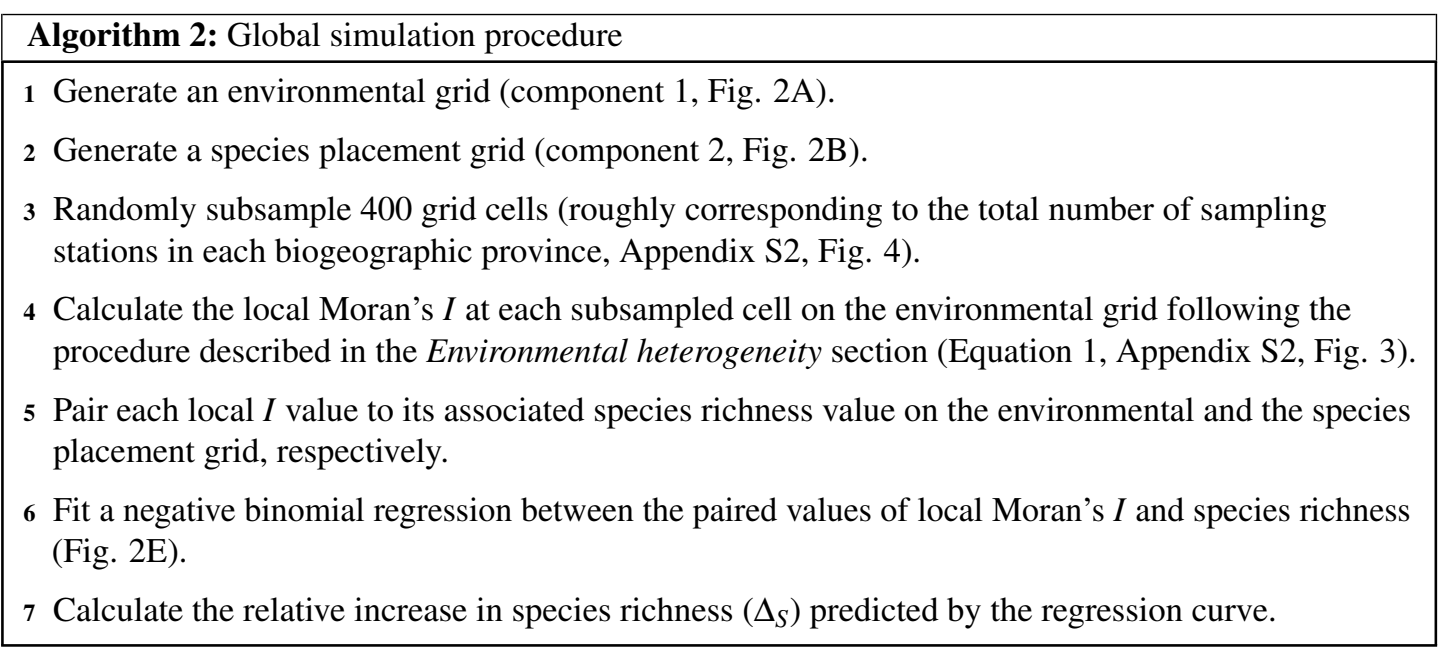

spurious negative relationship between richness and predictor variables (Fig. 2E). To represent this effect in the simulated data, we set three veil lines at percentiles $0 \%, 5 \%$ and $15 \%$ and excluded species richness values below these thresholds (Fig. 4).

\section{Statistical analyses}

We used regression analyses to examine the relationships between species richness and the scores from the first PCA axis of environmental variables. To determine whether environmental heterogeneity had an influence on species diversity for both observed and simulated data, negative binomial regressions were fitted to the points above the veil effect threshold using the $\mathrm{glm}$. nb function of the MASS package in R (version 3.0.1). We also checked for the presence of spatial autocorrelation in the model residuals.

\section{RESULTS}

Fish species richness was not correlated with any of the first three principal components from the analysis of environmental variables (Table 1; Fig. 3A, 3C), or with any of the individual environmental variables (results not shown). However, species richness was related to environmental heterogeneity (Fig. 3B and 3D). For both biogeographic provinces, the negative binomial regressions showed that species richness was greater in more heterogeneous environments (Fig. 3B and 3D). In the Virginian province (Fig. 3B), the mean species richness increased from 4.1 in the most homogeneous environments to 6.4 in the most heterogeneous environments, representing a gain of $2.3 \pm 0.11$ (95\% confidence limits) species which correspond to $56 \%$ relative increase. A similar pattern was found for the Louisianan province (Fig. 3D) where mean species richness increased from 3.6 in the most homogeneous environments to 8.5 in the most heterogeneous environments, representing a gain of $4.9 \pm 0.16$ (95\% confidence limits) species which correspond to $136 \%$ relative increase. We did not find spatial autocorrelation in the model residuals.

Averaging the results of 10000 model simulations, the mean species richness relative increase $\left(\Delta_{S}\right)$ were of $3.25 \%, 5.28 \%$ and $6.66 \%$ for the $0 \%, 5 \%$ and $15 \%$ veil effects, respectively (Fig. 4). The probabilities of observing $\Delta_{S}$ greater or equal to $56 \%$ (Virginian province) due to a sampling effect for different veils $(0 \%, 5 \%, 15 \%)$ were of $4.68 \%, 3.7 \%$ and $2.12 \%$, respectively (Table 2$)$. Considering a $\Delta_{S}$ of $136 \%$ threshold (Louisianan province), these probabilities dropped to $0.05 \%, 0.01 \%$ and $0 \%$ (Table 2).

\section{DISCUSSION}

Many factors, including environmental heterogeneity, have been reported to affect the diversity of aquatic communities (Field et al., 2009). However, it is likely that the set of factors influencing species richness differs across spatial and temporal scales (Fausch et al., 2002). Moreover, environmental heterogeneity has been identified as a key factor maintaining animal biodiversity in aquatic ecosystems (Levin et al., 2010). Our study combines data from extensive surveys and simulations to demonstrate a strong positive influence of environmental heterogeneity on the species richness of fish communities. Interestingly, species richness was associated with the spatial heterogeneity of environmental variables but not with 
their magnitude. For both biogeographic provinces, mean species richness in the most heterogeneous environments was markedly greater than in the most homogeneous environments, as quantified by the negative binomial regressions. Furthermore, the observed effect of heterogeneity on species richness was substantially greater (Fig. 3) than that generated by the simulations based on a random community assembly model, so it seems unlikely that the observed relationship arose solely as a byproduct of veil or sampling effects.

\section{Environmental variables}

Climate, energy, and primary productivity have a major influence on species richness at the regional, continental and global scales (Guégan, Lek, and Oberdorff, 1998; Hawkins, Field, and Cornell, 2003; Field et al., 2009). Studies conducted at small grain also indicate that environmental variables can influence species' occurrence and abundance in local fish communities in both space and time (Menge and Olson, 1990; Thiel et al., 1995; Rodríguez and Lewis, 1997). In contrast to these findings, we did not observe any direct effect of the magnitude of individual environmental conditions (Table 1), including salinity, chlorophyll- $a$ concentration and water temperature, on the species richness of local fish communities in either the Virginian (Fig. 3A) or Louisianan (Fig. 3C) biogeographic provinces.

In contrast with a simple randomization procedure, the simulation approach used in the random placement models allowed us to make a number of assumptions regarding the ecology of coastal fishes: 1) the spatial pattern of environmental conditions follows a two-dimensional power spectrum; 2) the centroid of each species on the seascape is determined by sampling from a uniform distribution and its range size by sampling from a power distribution; 3) fish species richness is independent from environmental conditions at the site of capture. We note that all three assumptions were supported by the empirical data. Another major assumption of random placement models is that the probability of finding a fish species at a particular site is independent of other species. Such ecological independence between co-occurring species has been shown to accurately reproduce a number of community patterns (McGill, 2010; McGill, 2011). For example, a recent study of shrubland plant communities reported that only 7 to $19 \%$ of all species pairs showed strong and consistent spatial associations, leading the authors to conclude that ecological processes are left no discernible spatial signature (Perry et al., 2014). In contrast with these findings, our results suggest that coastal fish communities may show a spatial signature, as fish species richness was not associated locally with the magnitude of environmental variables, but rather with their spatial heterogeneity.

\section{Environmental heterogeneity}

Environmental heterogeneity influences many ecological processes such as fluxes of organisms, material and energy among riverscape elements (Pickett and Cadenasso, 1995). Our results demonstrate that fish species richness responded positively to increased environmental heterogeneity (Fig. 3B and 3D) in both the Virginian and Louisianan biogeographic provinces. Simulations using a random placement model of community assembly showed that species richness increased only slightly in more heterogeneous environments (Fig. 4). For instance, less than 5\% of the 10000 simulations generated $\Delta_{S}$ greater than the conservative value of $56 \%$ observed in the Virgina biogeographic province (Fig. 3, Fig. 4, Table 2). Hence, it is unlikely that the positive relationship observed between environmental heterogeneity and species richness in both biogeographic provinces is the result of a sampling effect (sensu McGill, 2011).

Aquatic ecologists often use the term 'heterogeneity' rather loosely to refer to habitat complexity, habitat diversity or environmental variability over time (reviewed in Palmer, Menninger, and Bernhardt, 2010). For example, at small scales, heterogeneity usually refers to the variability in structural physical properties of the aquatic habitat such as riparian vegetation, channel configuration, artificial riffles and substrate granulometry (Palmer, Menninger, and Bernhardt, 2010). Conversely, studies conducted at regional or continental scales have used large-grained variables such as percentage of different types of biome or drainage area as a proxy for habitat heterogeneity (Guégan, Lek, and Oberdorff, 1998; Field et al., 2009; Oberdorff et al., 2011), possibly reflecting the difficulty of obtaining information at a finer resolution. Consequently, studies conducted at regional or continental scales are likely to capture broad-scale environmental heterogeneity that is coarse relative to the local heterogeneity to which individual fish respond, particularly for species having ranges smaller than the study grain size (O'Neill et al., 1986; Turner et al., 1989; Wiens, 1989). However, the question of which scale is optimal for quantifying the heterogeneity-diversity relationship is still open (Chase and Leibold, 2002; Durance, Lepichon, and Ormerod, 2006; Pittman et al., 2007). 


\section{Conclusions}

Over the last century, coastal ecosystems have become increasingly impacted by anthropogenic pressures (Lotze, Lenihan, et al., 2006), including many human-driven activities that reduce the temporal and spatial heterogeneity of coastal habitats. For example, commercial fish trawlers are known to reduce the spatial heterogeneity of the sea floor structure (Helfman, 2007). Similarly, the temporal variability of water flows in many of the world's largest rivers are regulated by dams (Nilsson et al., 2005). This reduced variability in runoffs has been shown to increase the homogeneity of water channels, as well as to degrade fish habitats (see Moyle and Mount, 2007 and references therein). The current study shows that, independently of the environmental conditions prevailing locally, more homogeneous habitats can support fewer fish species. Hence, restoring or actively protecting areas of high habitat heterogeneity appears to be of great importance for slowing actual trends of decreasing biodiversity in coastal ecosystems.

\section{ACKNOWLEDGMENTS}

We thank the U.S. Environmental Protection Agency's Environmental Monitoring and Assessment Program (EMAP) for freely providing their data. Although the data described in this article have been funded wholly or in part by the U.S. Environmental Protection Agency through its EMAP Estuaries Program, it has not been subjected to Agency review, and therefore does not necessarily reflect the views of the Agency and no official endorsement should be inferred. K. Roach made helpful comments on an earlier version of the manuscript. 


\section{REFERENCES}

Anselin, L. (1995). "Local indicators of spatial association — LISA." Geographical Analysis 27 (2), pp. 93-115.

Bejarano, I. and R. Appeldoorn (2013). "Seawater turbidity and fish communities on coral reefs of Puerto Rico." Marine Ecology Progress Series 474, pp. 217-226.

Bivand, R., with contributions by Micah Altman, L. Anselin, R. Assunção, O. Berke, A. Bernat, G. Blanchet, E. Blankmeyer, M. Carvalho, B. Christensen, Y. Chun, C. Dormann, S. Dray, R. Halbersma, E. Krainski, P. Legendre, N. Lewin-Koh, H. Li, J. Ma, G. Millo, W. Mueller, H. Ono, P. Peres-Neto, G. Piras, M. Reder, M. Tiefelsdorf, and D. Yu. (2013). spdep: Spatial dependence: weighting schemes, statistics and models.

Borcard, D., F. Gillet, and P. Legendre (2011). Numerical Ecology with R. New York, NY: Springer New York, p. 306.

Campos, P. R. A., A. Rosas, V. M. de Oliveira, and M. A. F. Gomes (2013). "Effect of landscape structure on species diversity." PloS one 8 (6), e66495.

Chase, J. M. and M. A. Leibold (2002). "Spatial scale dictates the productivity-biodiversity relationship." Nature 416 (6879), pp. 427-430.

Durance, I., C. Lepichon, and S. J. Ormerod (2006). "Recognizing the importance of scale in the ecology and management of riverine fish." River Research and Applications 22 (10), pp. 1143-1152.

Fausch, K. D., C. E. Torgersen, C. V. Baxter, and H. W. Li (2002). "Landscapes to riverscapes: bridging the gap between research and conservation of stream fishes." BioScience 52 (6), p. 483.

Field, R., B. A. Hawkins, H. V. Cornell, D. J. Currie, J. A. F. Diniz-Filho, J.-F. Guégan, D. M. Kaufman, J. T. Kerr, G. G. Mittelbach, T. Oberdorff, E. M. O’Brien, and J. R. G. Turner (2009). "Spatial species-richness gradients across scales: a meta-analysis." Journal of Biogeography 36 (1), pp. 132-147.

Gallant, J. C., I. D. Moore, M. F. Hutchinson, and P. Gessler (1994). "Estimating fractal dimension of profiles: A comparison of methods." Mathematical Geology 26 (4), pp. 455-481.

Guégan, J.-F., S. Lek, and T. Oberdorff (1998). "Energy availability and habitat heterogeneity predict global riverine fish diversity." en. Nature 391 (January), pp. 382-384.

Hale, S. S., M. M. Hughes, C. J. Strobel, H. W. Buffum, J. L. Copeland, and J. F. Paul (2002). "Coastal ecological data from the Virginian Biogeographic Province, 1990-1993.” EN. Ecology 83 (10), pp. 2942-2942.

Hawkins, B., R. Field, and H. Cornell (2003). "Energy, water, and broad-scale geographic patterns of species richness." EN. Ecology 84 (12), pp. 3105-3117.

Helfman, G. S. (2007). Fish Conservation: A Guide to Understanding and Restoring Global Aquatic Biodiversity and Fishery Resources. Washington DC: Island Press, p. 688.

Jackson, J. B. C. (2008). "Colloquium paper: ecological extinction and evolution in the brave new ocean." Proceedings of the National Academy of Sciences of the United States of America 105 Suppl, pp. $11458-11465$.

Kaiser, H. F. (1960). "The application of electronic computers to factor analysis." Educational and Psychological Measurement 20 (1), pp. 141-151.

Keitt, T. (2000). "Spectral representation of neutral landscapes." Landscape Ecology 15, pp. 479-493.

Kovalenko, K. E., S. M. Thomaz, and D. M. Warfe (2011). "Habitat complexity: approaches and future directions." Hydrobiologia 685 (1), pp. 1-17.

Kovesi, P. D. (2000). "MATLAB and Octave Functions for Computer Vision and Image Processing."

Kuffner, I. B., J. C. Brock, R. Grober-Dunsmore, V. E. Bonito, T. D. Hickey, and C. W. Wright (2006). "Relationships Between Reef Fish Communities and Remotely Sensed Rugosity Measurements in Biscayne National Park, Florida, USA.” Environmental Biology of Fishes 78 (1), pp. 71-82.

Levin, L. A., M. Sibuet, A. J. Gooday, C. R. Smith, and A. Vanreusel (2010). "The roles of habitat heterogeneity in generating and maintaining biodiversity on continental margins: an introduction." Marine Ecology 31 (1), pp. 1-5.

Lotze, H. K., H. S. Lenihan, B. J. Bourque, R. H. Bradbury, R. G. Cooke, M. C. Kay, S. M. Kidwell, M. X. Kirby, C. H. Peterson, and J. B. C. Jackson (2006). "Depletion, degradation, and recovery potential of estuaries and coastal seas." Science 312 (5781), pp. 1806-1809.

Lotze, H. K., K. Reise, B. Worm, J. van Beusekom, M. Busch, A. Ehlers, D. Heinrich, R. C. Hoffmann, P. Holm, C. Jensen, O. S. Knottnerus, N. Langhanki, W. Prummel, M. Vollmer, and W. J. Wolff (2005). 
"Human transformations of the Wadden sea ecosystem through time: a synthesis." Helgoland Marine Research 59 (1), pp. 84-95.

MacArthur, R. and J. MacArthur (1961). “On bird species diversity.” Ecology 42 (3), pp. 594-598.

MacArthur, R. H. and E. O. Wilson (1967). The theory of island biogeography. Princeton, N.J.: Princeton University Press, pp. xi, 203.

Mandrak, N. E. (1995). "Biogeographic patterns of fish species richness in Ontario lakes in relation to historical and environmental factors." en. Canadian Journal of Fisheries and Aquatic Sciences 52 (7), pp. 1462-1474.

McGill, B. and C. Collins (2003). "A unified theory for macroecology based on spatial patterns of abundance." Evolutionary Ecology Research 5, pp. 469-492.

McGill, B. J. (2010). "Towards a unification of unified theories of biodiversity." Ecology Letters 13 (5), pp. 627-642.

McGill, B. J. (2011). "Linking biodiversity patterns by autocorrelated random sampling." American Journal of Botany 98 (3), pp. 481-502.

Menge, B. A. and A. M. Olson (1990). "Role of scale and environmental factors in regulation of community structure." English. Trends in Ecology \& Evolution 5 (2), pp. 52-57.

Moyle, P. B. and J. F. Mount (2007). "Homogenous rivers, homogenous faunas." Proceedings of the National Academy of Sciences of the United States of America 104 (14), pp. 5711-5712.

Newman, M. (2005). "Power laws, Pareto distributions and Zipf's law." Contemporary Physics 46 (5), pp. 323-351.

Nilsson, C., C. Reidy, M. Dynesius, and C. Revenga (2005). "Fragmentation and flow regulation of the world's large river systems." Science 308 (5720), pp. 405-408.

Oberdorff, T., P. A. Tedesco, B. Hugueny, F. Leprieur, O. Beauchard, S. Brosse, and H. H. Dürr (2011). "Global and regional patterns in riverine fish species richness: a review." International Journal of Ecology 2011, pp. 1-12.

O’Neill, R. V., D. L. Deangelis, J. B. Waide, and G. E. Allen (1986). A hierarchical concept of ecosystems. Princeton University Press, p. 253.

Palmer, M. A., H. L. Menninger, and E. Bernhardt (2010). "River restoration, habitat heterogeneity and biodiversity: a failure of theory or practice?" Freshwater Biology 55 (Suppl. 1), pp. 205-222.

Perry, G. L. W., B. P. Miller, N. J. Enright, and B. B. Lamont (2014). "Stochastic geometry best explains spatial associations among species pairs and plant functional types in species-rich shrublands." Oikos 123 (1), pp. 99-110.

Pickett, S. T. and M. L. Cadenasso (1995). "Landscape ecology: spatial heterogeneity in ecological systems." Science 269 (5222), pp. 331-334.

Pittman, S., J. Christensen, C. Caldow, C. Menza, and M. Monaco (2007). "Predictive mapping of fish species richness across shallow-water seascapes in the Caribbean." Ecological Modelling 204 (1-2), pp. 9-21.

Preston, F. W. (1948). “The commonness, and rarity, of species.” Ecology 29 (3), pp. 254-283.

Proulx, R., I. T. Roca, F. S. Cuadra, I. Seiferling, and C. Wirth (2014). "A novel photographic approach for monitoring the structural heterogeneity and diversity of grassland ecosystems." Journal of Plant Ecology 7 (6), pp. 518-525.

Rabalais, N. N. (2002). "Nitrogen in aquatic ecosystems." Ambio 31, pp. 102-112.

Ricciardi, A. and J. B. Rasmussen (1999). "Extinction rates of north american freshwater fauna." Conservation Biology 13 (5), pp. 1220-1222.

Ricklefs, R. (1977). "Environmental heterogeneity and plant species diversity: a hypothesis." American naturalist 111 (978), pp. 376-381.

Rodríguez, M. A. and W. M. Lewis (1997). "Structure of fish assemblages along environmental gradients in floodplain lakes of the Orinoco River.” EN. Ecological Monographs 67 (1), pp. 109-128.

Seiferling, I., R. L. Proulx, and C. Wirth (2014). "Disentangling the environmental-heterogeneity-species-diversity relationship along a gradient of human footprint.” Ecology 95 (8), pp. 2084-2095.

Smokorowski, K. and T. Pratt (2007). "Effect of a change in physical structure and cover on fish and fish habitat in freshwater ecosystems - a review and meta-analysis." Environmental Reviews 15, pp. 15-41.

Thiel, R., A. Sepulveda, R. Kafemann, and W. Nellen (1995). "Environmental factors as forces structuring the fish community of the Elbe Estuary." Journal of Fish Biology 46 (1), pp. 47-69. 
Tisseuil, C., J.-F. Cornu, O. Beauchard, S. Brosse, W. Darwall, R. Holland, B. Hugueny, P. A. Tedesco, and T. Oberdorff (2013). "Global diversity patterns and cross-taxa convergence in freshwater systems." The Journal of Animal Ecology 82 (2), pp. 365-376.

Turner, M. G., R. V. O’Neill, R. H. Gardner, and B. T. Milne (1989). "Effects of changing spatial scale on the analysis of landscape pattern." Landscape Ecology 3 (3-4), pp. 153-162.

Wiens, J. A. (1989). "Spatial scaling in ecology.” Functional Ecology 3 (4), pp. 385-397.

With, K. A. (1997). "The application of neutral landscape models in conservation biology." Conservation Biology 11 (5), pp. 1069-1080.

Worm, B., E. B. Barbier, N. Beaumont, J. E. Duffy, C. Folke, B. S. Halpern, J. B. C. Jackson, H. K. Lotze, F. Micheli, S. R. Palumbi, E. Sala, K. a. Selkoe, J. J. Stachowicz, and R. Watson (2006). "Impacts of biodiversity loss on ocean ecosystem services." Science 314 (5800), pp. 787-790.

Yeager, L. A., C. A. Layman, and J. E. Allgeier (2011). "Effects of habitat heterogeneity at multiple spatial scales on fish community assembly." Oecologia 167 (1), pp. 157-68. 
1

Spatial distribution of sampling sites.

Spatial distribution of sampling sites for (A) Virginian and (B) Louisianan biogeographic provinces. Surveys were conducted by the U.S. Environmental Protection Agency's Environmental Monitoring and Assessment Program (EMAP) between 1990 and 1994.

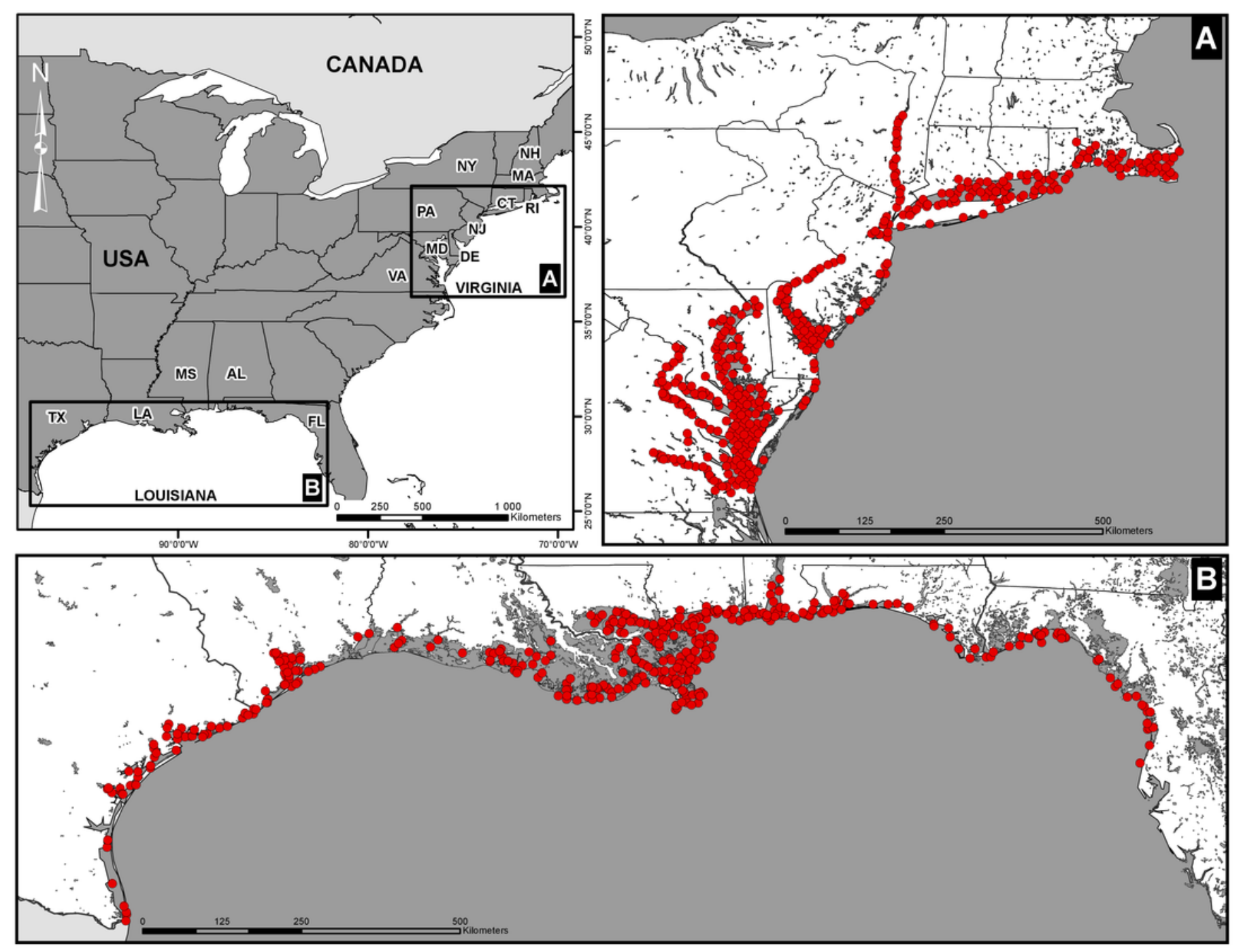




\section{2}

Framework of the random placement model of community assembly.

Framework of the random placement model of community assembly used to determine the relationship between fish species richness $(S)$ and habitat heterogeneity in the absence of any particular habitat selection mechanisms. Both environmental scores (A) and the species spatial distributions (B) were generated independently and parameterized using observed data. Habitat heterogeneity (C) and species richness (D), the two resulting model components, were superimposed such that each Moran's I value on the grid was associated to a value of species richness (E). $S_{\min }$ and $S_{\max }$ represent the range spanned by a fitted GLM negative binomial regression (red curve). To simulate possible artifacts due to unsampled fish (false 0 ), we added a veil effect threshold to the data generated by the model. A total of 10000 simulation were produced. 
A) Environment generation

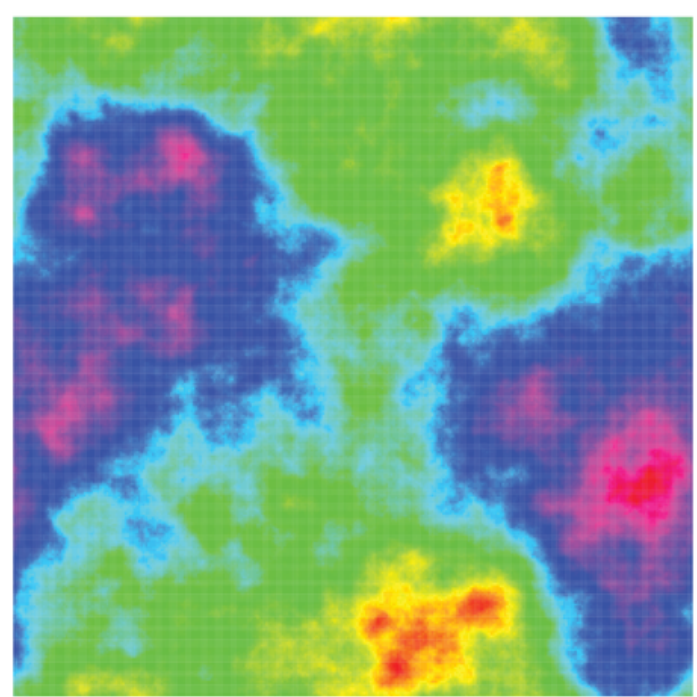

$\checkmark$

C) Local Moran (I)

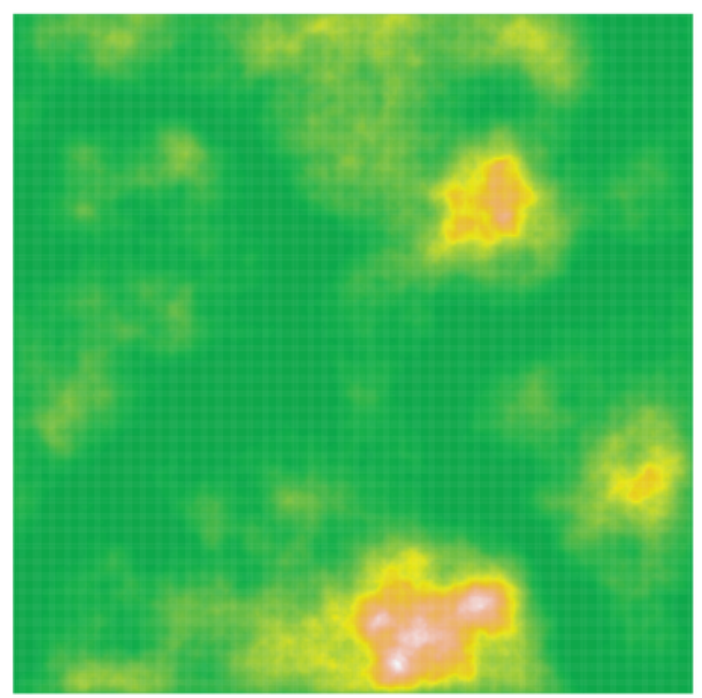

E) Mapping

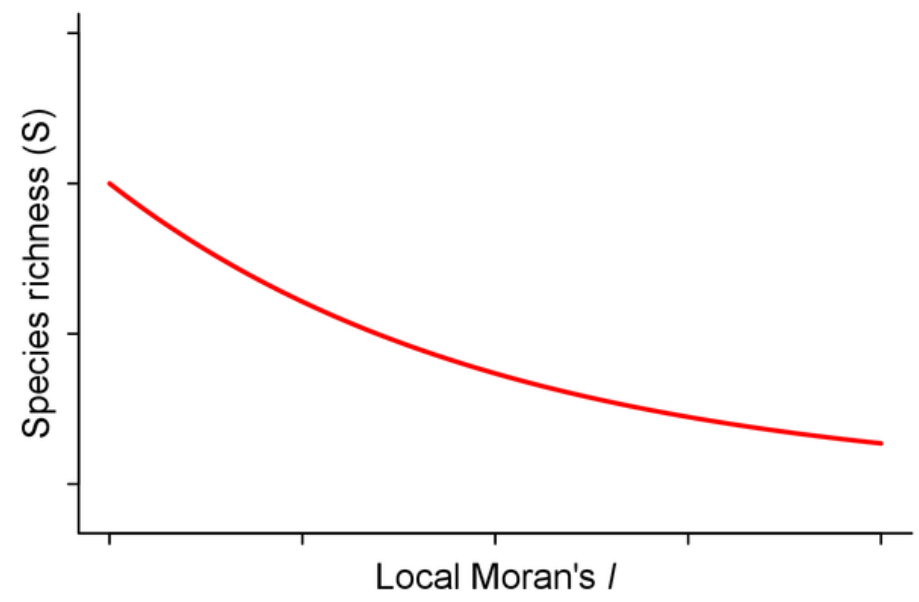

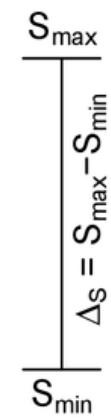

D) Species richness
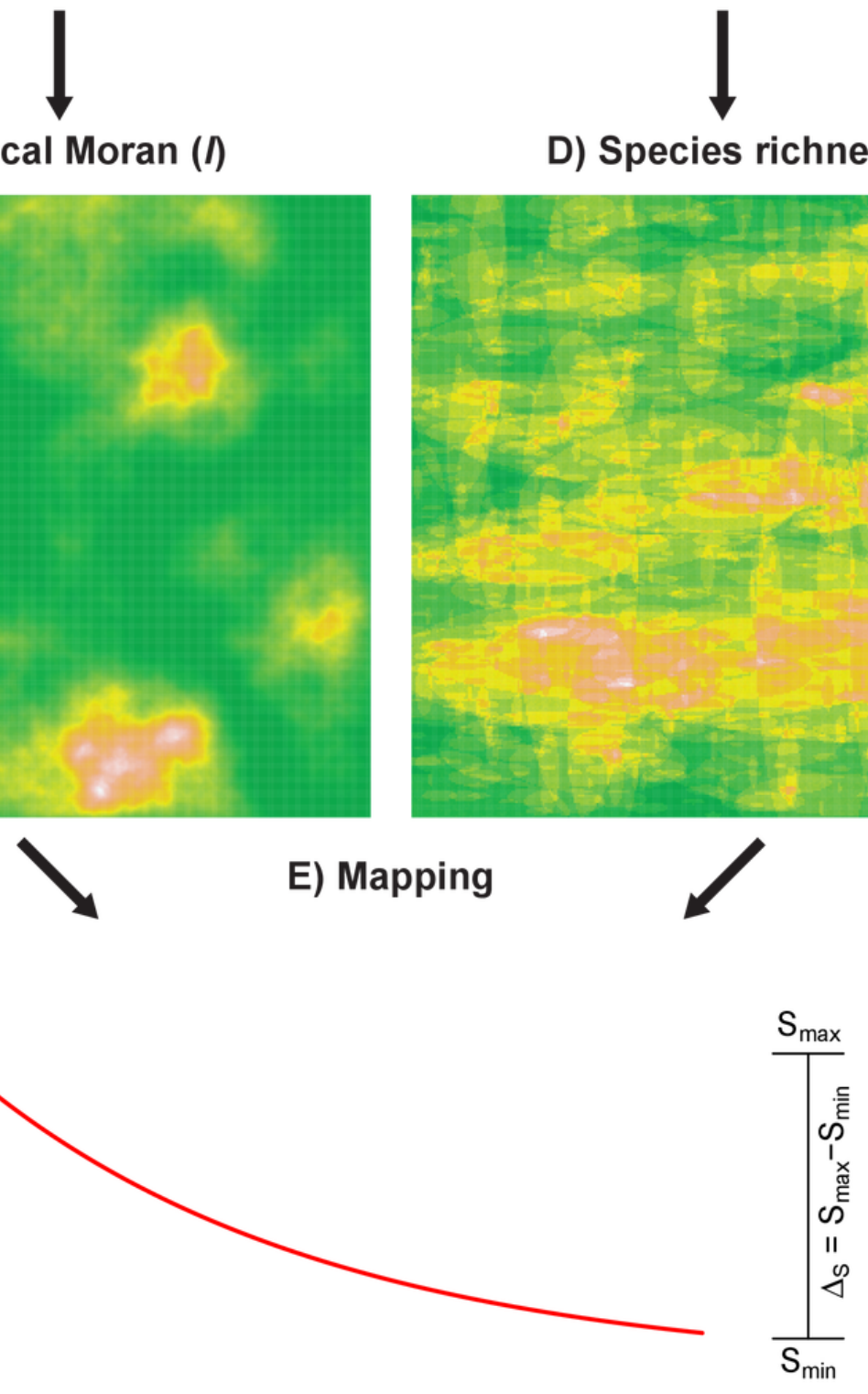

Local Moran's I
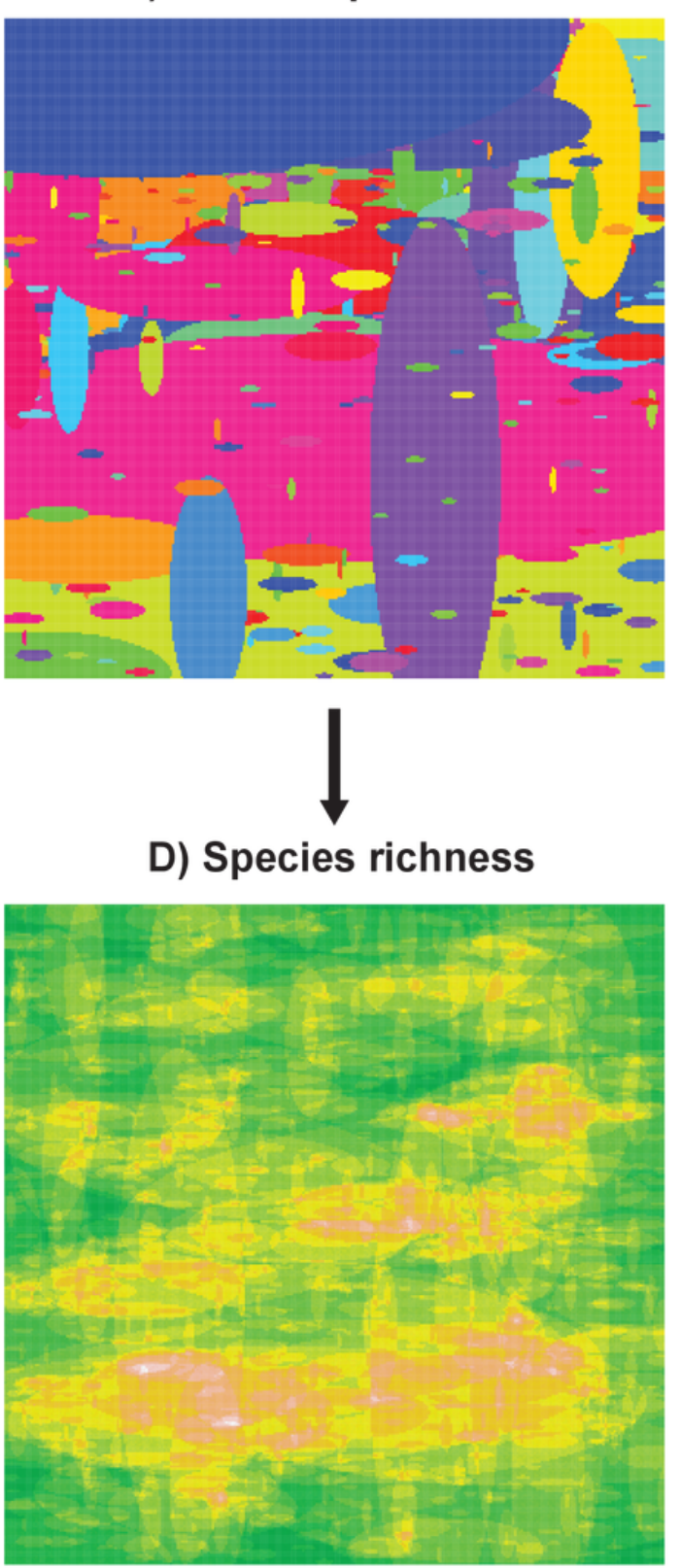

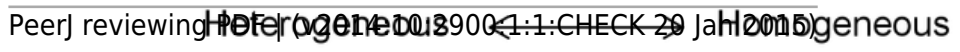


Relationships between species richness (S) and PCA scores.

Relationships between species richness (S) and PCA scores for the first axis (panels $\mathbf{A}$ and $\mathbf{C}$ ) and local Moran's I (panels B and D) for the Virginian and Louisianan biogeographic provinces. The red lines represent the fitted GLM negative binomial regressions between local Moran's I and $S$ (Virginian $p<0.001$, Louisianan $p<0.001$ ). The right-margin insets in panels $\mathbf{B}$ and $\mathbf{D}$ show the amplitude of species richness $\left(\Delta_{s}\right)$ described by the regression curves.

\section{Virginia}
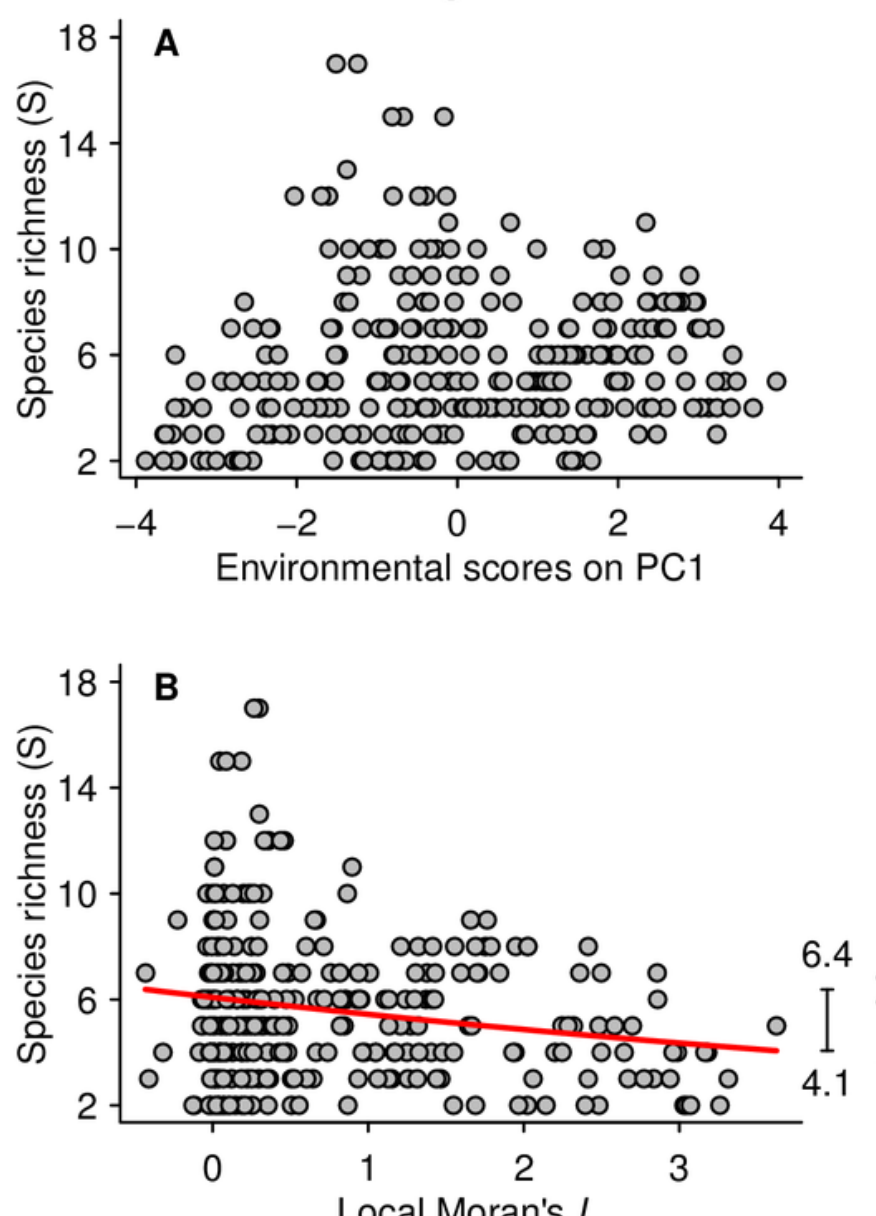

Heterogeneous $\longleftrightarrow$ Homogeneous

\section{Louisiana}
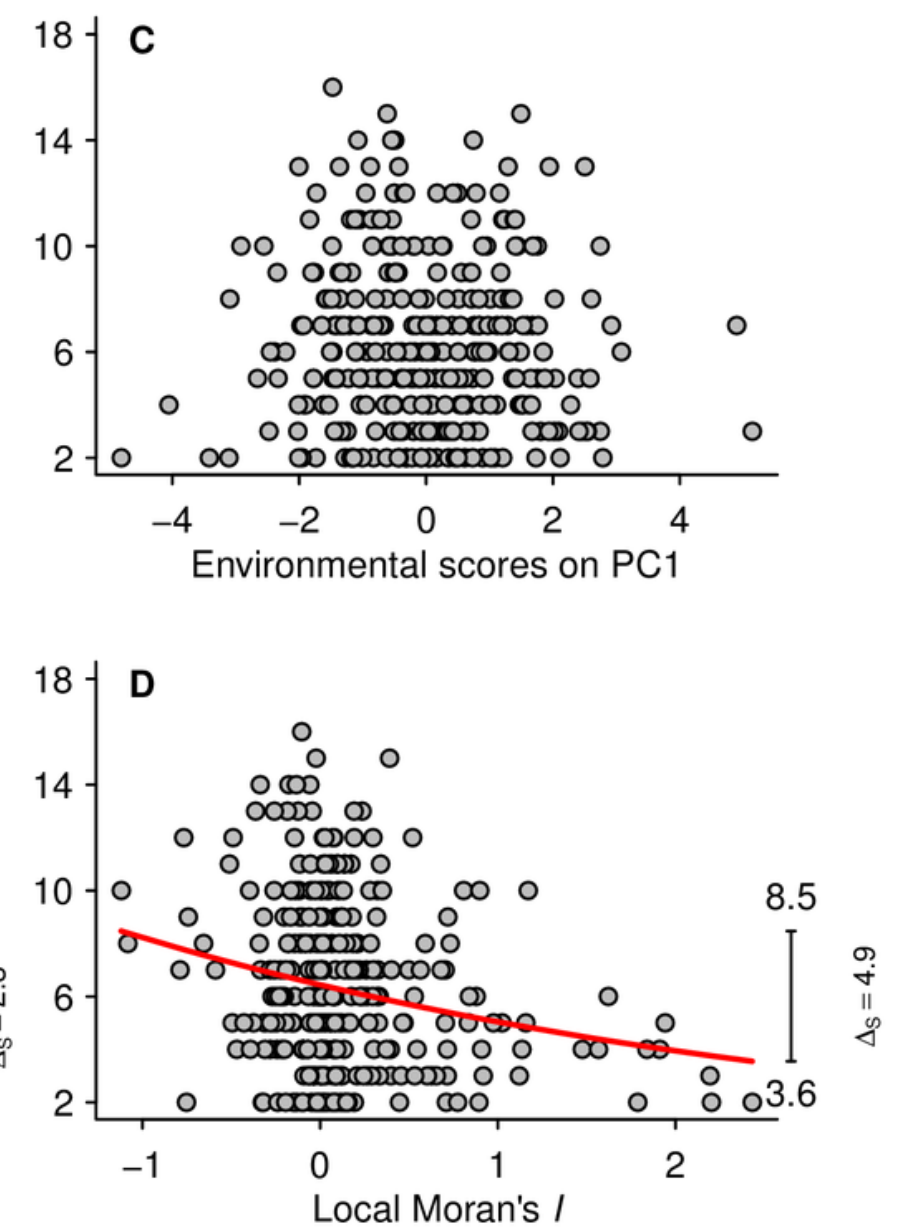

Heterogeneous $\longleftrightarrow$ Homogeneous 


\section{4}

Results of 10000 simulations showing the influence of quantile cut (veil effect) on modeled species richness.

Results of 10000 simulations showing the influence of quantile cut (veil effect) on modeled species richness. The green, red and blue areas represent the distribution of $\Delta_{\mathrm{s}}$ under veil effects of percentiles $0 \%, 5 \%$ and $15 \%$. The numbers in parentheses represent the mean of $\Delta_{\mathrm{s}}$ for each veil simulation. The arrows indicate the $\Delta_{\mathrm{s}}$ observed in the two biogeographic provinces.

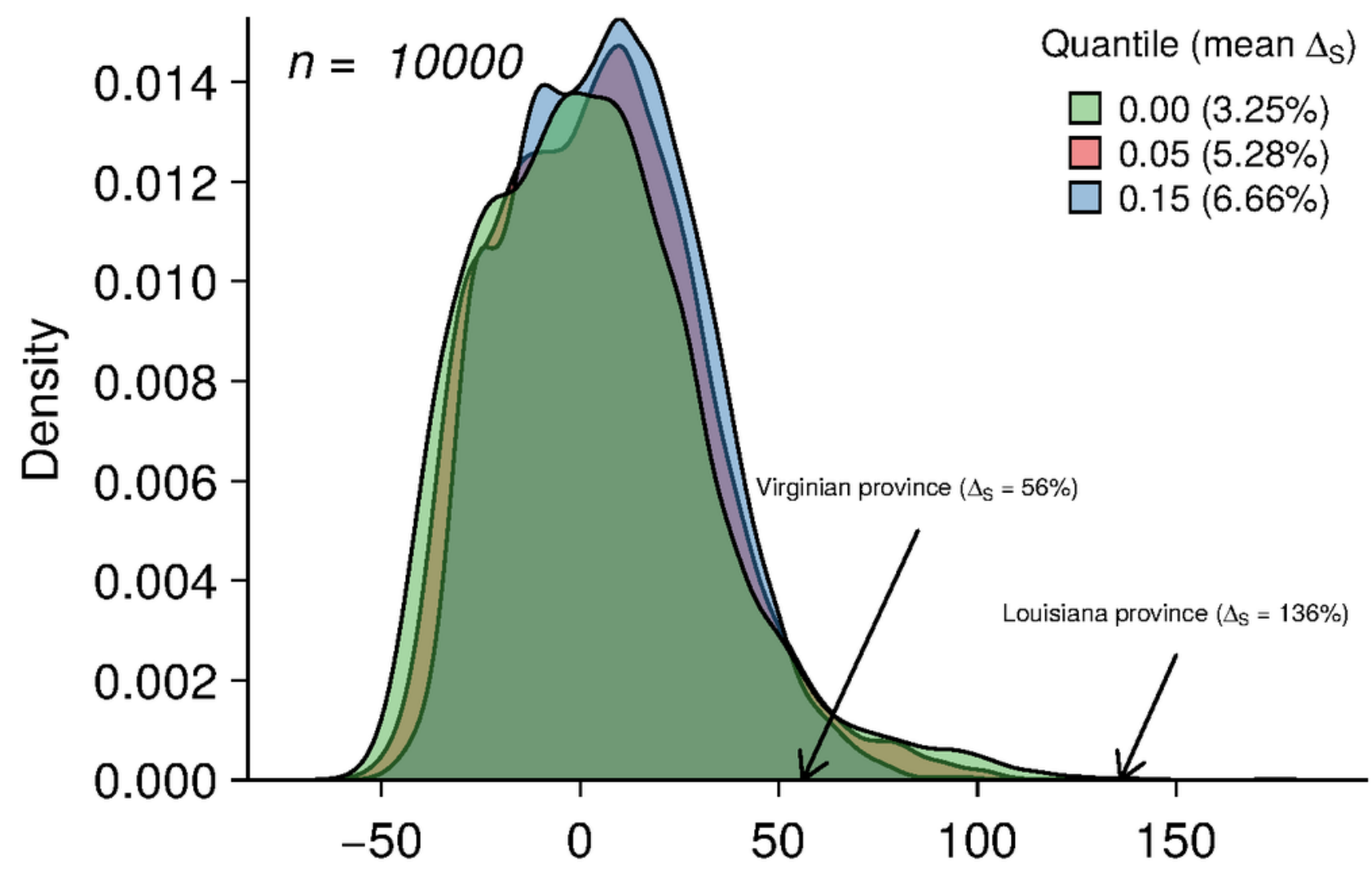

Variation in $\Delta_{S}(\%)$ 


\section{Table $\mathbf{1}$ (on next page)}

Table 1

Loadings and summary statistics for environmental variables. The first three principal components generated from environmental variables were retained based on Kaiser's criterion. These components explained $75 \%$ of the total environmental variability in both biogeographic provinces. 
Table 1: Loadings and summary statistics for environmental variables. The first three principal components generated from environmental variables were retained based on Kaiser's criterion. These components explained $75 \%$ of the total environmental variability in both biogeographic provinces.

\begin{tabular}{|c|c|c|c|c|c|c|c|c|c|c|c|c|}
\hline & Comp. 1 & Comp. 2 & Comp. 3 & & & & Comp. 1 & Comp. 2 & Comp. 3 & & & \\
\hline Water density $\left(\sigma_{t}\right)$ & -0.49 & 0.02 & 0.12 & 9.08 & 8.68 & $-4.36-23.94$ & & & & & & \\
\hline Dissolved oxygen $\left(m g L^{-1}\right)$ & -0.10 & -0.69 & 0.03 & 6.90 & 1.25 & $3.0-11.2$ & -0.42 & 0.55 & -0.10 & 6.89 & 1.33 & $3.4-14.8$ \\
\hline Fluorescence & 0.28 & -0.34 & 0.42 & 11.82 & 7.70 & $0-30$ & & & & & & \\
\hline $\operatorname{PAR}\left(m E m^{-2} s^{-1}\right)$ & -0.05 & -0.27 & -0.85 & 545.76 & 464.29 & $9-3621$ & -0.51 & -0.41 & -0.10 & 813.25 & 477.61 & $12-1870$ \\
\hline $\mathrm{pH}$ & -0.28 & -0.53 & 0.16 & 7.93 & 0.48 & $6.3-9.4$ & -0.40 & 0.47 & 0.41 & 8.00 & 0.46 & $5.3-9.5$ \\
\hline Salinity (ppt) & -0.49 & -0.00 & 0.11 & 16.18 & 11.05 & $0.03-32.89$ & -0.06 & -0.14 & 0.84 & 13.47 & 10.70 & $0.01-37.35$ \\
\hline Temperature $\left({ }^{\circ} \mathrm{C}\right)$ & 0.39 & -0.21 & -0.16 & 25.40 & 2.46 & $11.80-30.85$ & -0.50 & 0.02 & -0.32 & 29.77 & 1.41 & $24.7-34.0$ \\
\hline Transmissivity (\%) & -0.44 & 0.10 & -0.14 & 53.37 & 23.19 & $0-93$ & -0.39 & -0.54 & 0.11 & 63.97 & 16.12 & $2-133$ \\
\hline
\end{tabular}




\section{Table 2 (on next page)}

Table 2.

The probabilities of observing greater or equal than $56 \%$ (Virginian) or 136\% (Louisianan)

due to sampling effect (i.e. random) under different scenarios of veil effects $(0 \%, 5 \%, 15 \%)$. See Methods and Fig. 4 for detailed information. 
2 Table 2: The probabilities of observing greater or equal than 56\% (Virginian) or 136\% (Louisianan) due to sampling effect 3 (i.e. random) under different scenarios of veil effects $(0 \%, 5 \%, 15 \%)$. See Methods and Fig. 4 for detailed information.

4

\begin{tabular}{rrrr}
\hline & Veil at $0 \%$ & Veil at 5\% & Veil at $15 \%$ \\
\hline Virginian (56\%) & 4.68 & 3.70 & 2.12 \\
Louisianan (136\%) & 0.05 & 0.01 & 0.00 \\
\hline
\end{tabular}

5 